\title{
La pertinencia de los proyectos de innovación e investigación: entre lo global y lo local
}

Se hace una vez más significativo mencionar en este espacio la necesidad de repensar los cambios que requiere la Educación en nuestros países latinoamericanos. Para ello podemos visualizar dos rutas: una, con base en los grandes imperativos de la globalización, sustentada en las pruebas internacionales de organismos tales como: la Organización para la Cooperación y el Desarrollo Económica, OCDE, y su masiva prueba PISA por su sigla en ingles (programme for International Student Assessment) y otra, a partir de los estudios de necesidades contextuales y locales. Como la presentada en este número de la provincia de Córdoba, Argentina.

En este sentido, el mensaje de algunos de los artículos publicados en nuestra revista esta más cerca de la segunda ruta, pues como es natural, las investigaciones e innovaciones llevadas a cabo en contextos particulares son en su mayoría pertinentes localmente. La pretensión de la globalización, acompañada por los procesos de homogeneización están lejos de los docentes investigadores, afortunadamente desde nuestro punto de vista, aun cuando no así de los Ministerios de Educación y gobiernos de turno, quienes impulsan reformas basados en estos indicadores y bajo las perspectivas de la OCDE.

Como bien se conoce estas pruebas intentan indagar sobre determinadas áreas temáticas: lectura (2000); matemáticas ( 2003); ciencias ( 2006); lectura (2009); matemáticas ( 2012 ), áreas de importancia para la OCDE en el desarrollo económico. Recordemos algunos de sus objetivos "Contribuir a una sana expansión económica en los países miembros, así como no miembros, en vías de desarrollo económico". "Favorecer la expansión del comercio mundial sobre una base multilateral y no discriminatoria conforme a las obligaciones inter- nacionales". "Realizar la mayor expansión posible de la economía y el empleo y un progreso en el nivel de vida dentro de los países miembros, manteniendo la estabilidad financiera y contribuyendo así al desarrollo de la economía mundial." Ver (www.ine.cl/canales/ menu/OCDE/Queesla_OCDE/Queesla_OCDE.pdf )

Cuando leemos -en revistas de educación- resultados de procesos innovadores o investigaciones contextualmente pertinentes, nos encontramos con una serie de problemas que asechan a las comunidades escolares, los cuales están lejos de las áreas temáticas tan importantes para las pruebas censales. Por ejemplo, el sentido de una formación ciudadana, intercultural que garantice verdaderos procesos de convivencia y que supere las xenofobias, la inequidad de nuestros sistemas educativos, el irrespeto a la diversidad cultural, etc. O los problemas cada vez más graves que los estudiantes están viviendo, dificultades inimaginables por los adultos: padres o maestros; sabemos que los jóvenes están siendo cada vez más educados y formados por los medios de comunicación, por las redes sociales, al margen de los sistemas educativos formales, los síntomas de sus problemáticas aparecen como elementos exóticos que se asoman tímidamente en proyectos de innovación o investigación en las instituciones educativas (las cuales seguramente no hacen parte de las investigaciones de frontera en la esfera de los intelectuales de la educación internacional), las culturas juveniles se revelan como antagónicas a los parámetros de las sociedades contemporáneas marcadas, por ejemplo, por un consumismo exacerbado. Las soledades de niños y jóvenes -aun cuando pertenecen a redes sociales robustas-cada vez los hacen experimentar a temprana edad depresiones profundas que dejan significativamente huellas en su 
parte emocional. Estos trabajos como podemos reconocer se encuentran muy lejos de las preocupaciones de los organismos internacionales.

Esto mismo sucede con los cambios exigidos por la comunidad académica y los Ministerios de Educación a las Facultades y Universidades que forman los futuros docentes. Así, si dichas Facultades de Educación basan sus reformas curriculares en los resultados de las evaluaciones nacionales o internacionales, serán unos los cambios que establezcan a los programas en donde se forman sus licenciados, y otras las renovaciones de los programas si se atiende a los problemas contextualmente relevantes, donde los contextos revelan singularidades que deben ser atendidas desde los sistemas educativos.

Es de todos conocido que los docentes están siendo formados en programas -con registros calificados y acreditaciones de alta calidad-con rigurosos procesos disciplinarios y áreas temáticas bien definidas, pero que dichos programas no los habilitan del todo para aproximarse o comprender las esferas emocionales de sus alumnos.

Las urgencias de muchos docentes están más centradas en la formación disciplinar, en la administración de los currículos sin reparar en una formación para la vida, entonces sucede lo que estamos viviendo, los estudiantes acuden a la escuela a aprender que la obediencia es el camino del éxito escolar. Para ellos, aprender algunos procedimientos y llenarse de información los habilita en las pruebas censales o a promoverse de grado. Pero no encuentran en las largas jornadas espacios para construir referentes de vida, se hace cada vez más explicito que los estudiantes no reconozcan a sus profesores como posibles referentes o personas ni siquiera para entablar conversaciones tranquilas, las aulas entonces se vuelven espacios estériles donde los estudiantes no encuentran respuestas a sus preguntas y menos respuestas a los problemas sociales, ambientales o culturales de su entorno.

Fuera de las instituciones escolares están las verdaderas expectativas de vida de los escolares, están las redes sociales, sus amigos, los retos de hacerse ciudadanos, los significativos problemas de su entorno, del deterioro ambiental, de la ética, de la formación en la dignidad.

El reto de la educación, insistimos, es dotar de sentido las actividades escolares, más allá de los currículos. Con ello nos referimos a la necesidad de comprender los contextos y las problemáticas cotidianas de la realidad próxima para llevarlos a las aulas a fin de construir colectivamente propuestas de solución. Con esta decisión no solo lograremos que las actividades de clase posean sentido para maestros y estudiantes, sino que la escuela como un todo consiga dar cuenta de su compromiso con la sociedad contribuyendo a su transformación. Así pues, aun cuando se sacrifiquen las exigencias internacionales puntuales que se plantean a través de las pruebas censales, si los jóvenes vivencian procesos de construcción de alternativas de solución a sus propios problemas (lo que les exige habilidades lectoras y procesos de articulación de la información con la experiencia en contextos de creatividad e imaginación) seguramente estarán más capacitados para comprender y obtener resultados satisfactorios en dichas pruebas. Ya es hora de intentarlo.

Clara Inés Chaparro Susa 